HID 40 (2013)

\title{
ORDENANZAS SOBRE EL AZÚCAR DE CAÑA EN EL SIGLO XVI. UN ANÁLISIS COMPARATIVO ${ }^{1}$
}

\author{
ORDINANCES GOVERNING CANE SUGAR IN THE $16^{\mathrm{TH}}$ CENTURY: A \\ COMPARATIVE ANALYSIS.
}

\author{
ANA Viña BRITO \\ Universidad de La Laguna \\ anvina@ull.es
}

RESUMEN: Las ordenanzas sobre el azúcar en las islas del Atlántico, en el siglo $\mathrm{XVI}$, tienen su referente en las áreas jurisdiccionales en las que se integran las respectivas islas, la monarquía lusitana y la castellana. El desarrollo alcanzado en estos territorios, con una modificación del espacio físico y una economía basada en la caña de azúcar, trajo consigo un gran desarrollo de la normativa local que, a grandes rasgos, se trasvasará al mundo americano, lo que nos permite realizar un estudio comparativo entre las distintas zonas azucareras del sudeste andaluz, Madeira, Canarias, Santo Domingo y La Habana.

PAlABRAS ClaVE: Ordenazas, caña de azúcar, islas atlánticas, siglo XVI.

ABSTRACT: The ordinances governing sugar in the islands of the Atlantic in the 16th century have their frames of reference in the administrative systems pertaining to the various islands, the Portuguese and the Spanish monarchies. The development attained in these territories, entailing the modification of the enviroment and an economy based on sugar cane, brought with it a major development in the local legal system, whose broad features would later be transferred to the american colonies. This allows us to carry out a comparative study of the sugar producing areas in south eastern Andalusia, in Madeira, the Canaries, Santo Domingo, and Havana, Cuba.

KEYWORDS: Ordinances, sugar cane, Atlantic Islands, 16th century.

1. Este trabajo forma parte del proyecto de investigación La terminología azucarera atlántica: documentación e historia, subvencionado por el Ministerio de Ciencia e Innovación (FF12010-19422). 
Tengan cada uno en su ingenio el treslado de las hordenanças tocante a los açucares

(Ordenanzas de Gran Canaria)

Desde hace varias décadas las ordenanzas han sido una de las fuentes de estudio para el derecho local y el conocimiento de la realidad municipal, y mucho más en Canarias que, a diferencia de lo que sucedía en las vecinas islas del Atlántico, Madeira y Azores, donde prima la acción intervencionista de la corona, las ordenanzas se van elaborando por los distintos cabildos de manera más autónoma y uniforme.

Este hecho no quiere decir que toda la normativa local canaria, al igual que la de las áreas americanas bajo jurisdicción española, no tenga su referencia en la corona castellana sino que, por las peculiaridades de los cultivos implantados en alguna de las islas en los inicios de la colonización, estas ordenanzas presentan algunas novedades respecto a sus homónimas castellanas, pues ya desde muy temprano tanto las ordenanzas de Santo Domingo o La Habana como las canarias siguen el patrón peninsular. Aunque primero se legisla en los asuntos referentes al cabildo para después tratar los temas económicos, en las ordenanzas de estas regiones se convierte en fundamental el factor económico y, especialmente, todo lo relacionado con el azúcar en torno al cual girará la vida de estas zonas.

Uno de los ejemplos más evidentes fue el cabildo de Santo Domingo que llegó incluso a intervenir activamente en el proceso de producción y comercialización del azúcar, pues la mayoría de sus miembros eran señores de ingenio que asumieron gran parte del control de las actividades azucareras desde sus puestos políti$\cos ^{2}$, o en Canarias donde a través de las actas de los cabildos vemos que buena parte de los propietarios de cañas e ingenios eran los mismos regidores, teniendo el concejo en muchas ocasiones que solicitar a la corona disposiciones relativas a la obligatoriedad de que los dueños de ingenios y cañas se ausentasen de las sesiones cuando se trataran asuntos relativos a la caña de azúcar³.

Nuestro propósito, a pesar de las dificultades, es realizar un estudio comparativo entre las Ordenanzas del azúcar de Canarias ${ }^{4}$, Madeira, el sureste peninsular, sobre todo de los núcleos del antiguo reino de Granada productores de caña ${ }^{5}, \mathrm{y}$ algunas del Nuevo Mundo, fundamentalmente de las islas del Caribe, con la finalidad de plasmar paralelismos o situaciones, lo que nos ayudará a profundizar en el

2. J. DEL RÍO MORENO y L. LÓPEZ SEBASTIÁN. "El comercio azucarero antillano en el siglo XVI: el marco legal y la expectativa local", Producción y Comercio del azúcar de caña en época preindustrial. Actas del Tercer Seminario Internacional. Granada, 1993, p. 165.

3. A. VIÑA BRITO y M. RONQUILLO RUBIO. "El primer ciclo del azúcar en Canarias. Balance historiográfico", Seminario El azúcar y el mundo Atlántico. XVI Coloquio de Historia Canario Americana (CHCA). Las Palmas de Gran Canaria, 2006, p. 260.

4. Era este el principal cultivo de exportación y como tal queda plasmado en las ordenanzas de las cuatro islas del azúcar: Gran Canaria, Tenerife, La Gomera y La Palma.

5. Analizamos las ordenanzas de algunas localidades granadinas que, aunque están insertas en la etapa de producción azucarera mediterránea, al ser muchas de ellas coetáneas a las de la etapa atlántica presentan muchas coincidencias. 
conocimiento de las comunidades locales y formas de organización similares. Esto supondrá abandonar el tradicional enfoque localista, a fin de comparar con una perspectiva más amplia las ordenanzas sobre el azúcar de diversas procedencias a lo largo del siglo XVI.

En este estudio comparativo plantearemos las diferencias geográficas que condicionan las áreas susceptibles de cultivo y el proceso de transformación en relación directa con los recursos naturales: su análisis resulta imprescindible para poder comprender las peculiaridades de los distintos ordenamientos, como puede ser el hecho de que en Canarias respecto a Madeira el agua es mucho más escasa y los recursos forestales más limitados frente a las enormes extensiones del Nuevo Mundo o, el espacio susceptible de cultivo queda reducido a terrazas y bancales en Canarias. Aunque los cañaverales fueron elementos propios del paisaje de las denominadas "islas del azúcar", en el archipiélago la producción fue menos cuantiosa y supuso un esfuerzo suplementario tanto por lo accidentado del terreno como por la escasez o lejanía de las aguas. Lo que no cabe duda es que en todos los territorios se modificó el medio físico pero, en el caso de las islas atlánticas, especialmente Canarias y Madeira, se partía de un hecho diferente a lo que sucedía en la zona granadina y fue la posibilidad de modificar totalmente el medio físico y adaptarlo a la nueva economía azucarera con una convivencia mayor entre plantaciones e ingenios.

Un segundo aspecto previo y significativo que se debe tener en cuenta a la hora de establecer este análisis es advertir las diferencias derivadas del ámbito de jurisdicción portuguesa o castellana, pues como señalaba Polo Martín ${ }^{6}$ : la incorporación de nuevos territorios a la corona de Castilla a fines del siglo XV, Granada y Canarias, dispensó a los Reyes Católicos la oportunidad de ensayar un régimen municipal en las ciudades conquistadas que, aún ofreciendo semejanzas con los modelos vigentes en Castilla, vino a introducir peculiaridades favorables al común de los vecinos. Por el contrario en Madeira, como ha estudiado A. Vieira ${ }^{7}$, resalta el carácter precario del ordenamiento y el permanente cambio de código de las ordenanzas, lo que conduce a compilaciones y alteraciones de su articulado. Y es que la originalidad de los municipios canarios respecto a los de Madeira y Azores estribaba en que gozaban de una más amplia capacidad legislativa.

Por su parte, en el mundo americano la situación fue diferente ya que, a falta de grandes núcleos urbanos, en los primeros momentos el señor de ingenio actuaba prácticamente de forma autónoma y con posterioridad pasaría a ocupar cargos relevantes en el cabildo, por lo que el ordenamiento concejil se orientaría en su propio beneficio, convirtiéndose el regimiento en la representación de los intereses particulares, como sucedió en La Española, donde la mayor parte de los oidores y oficiales de la Audiencia se relacionaron con las grandes plantaciones, de forma

6. R. POLO MARTÍN. El régimen municipal de la Corona de Castilla durante el reinado de los Reyes Católicos (organización, funcionamiento y ámbito de actuación). Madrid, 1999, p. 757.

7. A. VIEIRA. "As posturas municipais dos Açores e Madeira nos séculos XV a XVII", Boletim do Instituto Histórico da Ilha Terceira, Angra do Heroismo, XLIX (1991), pp. 31-52. CEHA Biblioteca Digital. 
privada, llegando casi todos ellos a ser señores de ingenio y a actuar como tales, a la vez que asumían sus funciones administrativas, lo que supuso una clara coincidencia entre gobierno del territorio e intereses privados ${ }^{8}$.

Esta situación derivaba de lo acaecido en los inicios de la colonización pues, entre los años 1516-1518, las únicas zonas pobladas del Nuevo Mundo eran las islas del Caribe y alrededor de los molinos de azúcar se fueron creando nuevos asentamientos con villas prósperas de población permanente. Serán estas aglomeraciones en torno a los "complejos agroindustriales" los núcleos desde los que se ejercería la autoridad, al no implantarse ningún tipo de estructura administrativa, ni ayuntamiento en los primeros momentos, por lo que el señor del molino se convertiría en el único foco de autoridad en la región'.

También en Madeira y Canarias la presencia de un ingenio contribuyó decididamente al desarrollo de nuevos núcleos poblacionales. Baste recordar, en La Palma la importancia que adquirió el núcleo de San Andrés, que llegó a tener alcalde pedáneo y escribano, y que la existencia del ingenio y la morada de los trabajadores en Los Sauces trajo consigo el desarrollo de esta zona que constituirá posteriormente una municipalidad; o en Gran Canaria donde, según señalan las Sinodales de Vázquez de Arce de 1515, se crean nuevas parroquias porque se habían plantado muchas cañas, o ya en la segunda mitad del XVI en el sur de Tenerife, en Adeje, la instalación de un ingenio junto a la casa fuerte del señorío originó el surgimiento de un nuevo núcleo poblacional.

Lo que no cabe duda es que, a pesar de las peculiaridades que el ordenamiento tiene en cada territorio, los orígenes comunes llevarían a que en muchos aspectos las semejanzas se mantuvieran.

Si la geografía y la organización político administrativa fueron importantes, otro aspecto que llama la atención es la disparidad de documentación relativa al ordenamiento local sobre la caña de azúcar en el área castellana, como se ha puesto de manifiesto, entre otros, para el caso de Salobreña y, en general, en toda la vega del río Guadalfeo desde época nazarí ${ }^{10}$ y lo mismo sucede si comparamos las "islas azucareras" con el Nuevo Mundo.

Si bien es verdad que hoy día las ordenanzas las conocemos fundamentalmente por recopilaciones y libros de acuerdos municipales ${ }^{11}$, por peticiones o quejas de los vecinos o por mandato expreso de la corona, se nos plantean algunas dificultades por el hecho de que no todos los acuerdos concejiles recogidos en las actas capitulares pasaron a formar parte de las ordenanzas. También es necesario tener en cuenta que las sucesivas compilaciones que se conservan del siglo XVI eran acordes con los criterios que en cada momento utilizaban los concejos, lo que en

8. J. DEL RÍO MORENO y L. LÓPEZ SEBASTIÁN. Ob. cit., p. 164.

9. J. DEL RÍO MORENO. Los inicios de la agricultura europea en el Nuevo Mundo. Sevilla, 1991, p. 465.

10. Véase a modo de ejemplo A. MALPICA CUELLO. (Ed.) Paisajes del Azúcar. Actas del Quinto Seminario Internacional. Granada, 1995.

11. A veces una misma ordenanza es recogida en varios acuerdos capitulares, ordenándose su publicación en fecha diferentes. 
modo alguno significaba que se recogieran todas las ordenanzas vigentes ni, por supuesto, que las que no se incluían se derogasen. Así por ejemplo el cabildo de Tenerife acordó el pregón de la ordenanza del azúcar el 19 de mayo de 1504 que posteriormente amplió y volvió a pregonar como ordenanza el 19 de febrero de $1507^{12}$.

La elección de las ordenanzas sobre el azúcar en Canarias como epicentro de este análisis viene determinada por varias razones. La primera porque fue el principal cultivo de exportación tras la incorporación de las islas a la corona castellana, en segundo lugar porque en torno a las plantaciones e ingenios se constituyeron los principales núcleos de población y también sirvió de ensayo para los desarrollados en el Nuevo Mundo y, sobre todo porque, como han señalado varios autores ${ }^{13}$, entre las dos etapas claramente diferenciadas de la historia del azúcar, la mediterránea y la americana, se encuentra la de las islas atlánticas, "auténtica plataforma de expansión y comercio de un producto esencial de la economía-mundo que se gestó a finales del XV y en el XVI"14. Las islas atlánticas fueron conquistadas y puestas en explotación de tal manera que de forma inmediata se mostraron como escenarios magníficos para el surgimiento de una nueva economía azucarera.

Las ordenanzas madeirenses son cronológicamente anteriores a las de Canarias, pero la extensión de estas últimas nos permite conocer no solo las influencias recibidas sino también la experiencia acumulada como lugar de paso y ensayo del modo de producción azucarero mediterráneo que pronto serviría de modelo en otras regiones. Sirva como ejemplo el caso del cabildo de Santo Domingo que solicitó licencia a la corona para llevar de Canarias maestros de azúcar ${ }^{15}$ o también la emigración de familias canarias a Santo Domingo como se observa, entre otras, en la capitulación de 1545 para el transporte de 30 familias concedida a Francisco de Mesa, vecino de Gran Canaria, quién señala explícitamente su intención de ir a entender en azúcares ${ }^{16}$.

Esta influencia se observa en muchos aspectos, como en el conflicto surgido por la percepción de los diezmos y más concretamente en la forma de diezmar los azúcares en Santo Domingo o en Méjico. Para solventar el enfrentamiento el obispo de Taxcala apeló al caso de Canarias para diezmar los azúcares en Veracruz en el año $1538^{17}$. Estas referencias son solo una muestra de esa influencia y nos lleva a afirmar, como señaló Humberto López Morales, que la organización interna de

12. E. SERRA RÀFOLS. Acuerdos del Cabildo de Tenerife, 1497-1507. La Laguna, Instituto de Estudios Canarios, Fontes Rerum Canariarum (FRC), 1996², docs. nº 391 y 713.

13. A. MALPICA CUELLO y A. FÁBREGAS GARCÍA. "La producción de azúcar en el ámbito doméstico", O Açucar e o Quotidiano. Madeira, 2004, p. 31.

14. A. MALPICA CUELLO. "Medio físico y territorio: el ejemplo de la caña de azúcar a finales de la Edad Media", Paisajes del Azúcar. Actas del Quinto Seminario Internacional. Granada, 1995, p. 20 .

15. G. RODRÍGUEZ MOREL. "La mano de obra esclava en las plantaciones azucareras de Santo Domingo", O Açucar e o Quotidiano. Madeira, 2004, p. 80.

16. A. GUTIÉRREZ ESCUDERO. "Los canarios, el azúcar y el desarrollo agrícola de Santo Domingo (Siglo XVIII)", Seminario El azúcar y el mundo Atlántico. XVI CHCA. Las Palmas de Gran Canaria (2006), p. 98.

17. 1538, febrero, 26. AGI México, 1088. L. 3, f. 4v. 
los grandes ingenios "habría sido trasplantada in solidum de Canarias al igual que la terminología técnica, copiada de Canarias"18.

En comparación con las ordenanzas del sureste andaluz, el ordenamiento canario sobre el azúcar se encuentra mucho más desarrollado y es incluso anterior en su redacción al del mediodía peninsular. Ya señalaba Ladero Quesada que si alguna novedad presentan las ordenanzas del archipiélago respecto a las peninsulares es en lo referente a la temática azucarera, "la regulación de la especiería no tiene parangón en las ordenanzas andaluzas" "19. A pesar de esta afirmación y de otras hipótesis planteadas, consideramos que no podríamos hablar de un modelo económico propio en lo relativo a la caña de azúcar para Canarias que sería trasportado a América, aunque sí probablemente para la primera economía atlántica, de Madeira y Canarias, en los inicios del siglo XVI, pues como manifestaba Magalhaes Godhino $^{20}$, la agricultura fue la motivación fundamental de la colonización portuguesa en el norte de África y en las islas del atlántico, y el azúcar su producto principal.

Cierto paralelismo puede vislumbrarse en el territorio americano perteneciente a la corona española pues, aparte de la riqueza en metales, se propugnó el asentamiento de plantaciones azucareras, tal como se recoge por ejemplo en las capitulaciones de 1532 con Pedro de Heredia ${ }^{21}$. Señalaba Antonio de Herrera, uno de los primeros historiadores indianos, que la caña de azúcar llevada desde Canarias se aclimató en las Antillas al tiempo que las primeras medidas protectoras del cultivo se implantan, pasando pronto de una isla a otra del Caribe ${ }^{22}$. La conquista de tierras americanas proporcionó nuevos territorios favorables al cultivo de la caña con especial desarrollo en Brasil y, por supuesto, en Cuba, Jamaica y Santo Domingo y poco tiempo después en Méjico, pero no sería hasta la segunda mitad del siglo XVI cuando se apueste decididamente por la caña de azúcar para implantarla a gran escala.

Para este análisis hemos utilizado las ordenanzas publicadas para Madeira e islas del Caribe, especialmente las de La Habana de 1574 y los acuerdos del cabildo de Santo Domingo, así como las granadinas y los estudios que sobre ellas se han editado, ya fuera ediciones facsímiles, transcripciones o referencias bibliográficas puntuales, como las de Almuñécar ${ }^{23}$, Motril o las propias ordenanzas de Granada

18. H. LÓPEZ MORALES. "Orígenes de la caña de azúcar en Iberoamérica”, La caña de azúcar en tiempos de los grandes descubrimientos, 1450-1550. Actas del Primer Seminario Internacional. Granada, 1989, p. 206. Esa influencia se observa también en la terminología Véase: C. CORRALES y D. CORBELLA, "La formación del léxico azucarero en Canarias ", Seminario El azúcar y el Mundo Atlántico. XVI CHCA. Las Palmas de Gran Canaria (2006), pp. 11-35.

19. M.A. LADERO QUESADA, “Ordenanzas Municipales y regulación de la actividad económica en Andalucía y Canarias. Siglos XIV-XVII”, II CHCA. Las Palmas de Gran Canaria (1979), p. 154.

20. V. MAGALHAES GODINHO. Os descobrimentos e a economía mundial. Lisboa, 1971, T. III, pp. 217-280.

21. J. DEL RÍO MORENO. Ob. cit., p. 325.

22. F. MORALES PADRÓN. El comercio canario americano (siglos XVI, XVII y XVIII). Homenaje a D. Francisco Morales Padrón. Las Palmas de Gran Canaria, 2011, p. 41.

23. Para Almuñécar son ocho acuerdos municipales de 1516 a 1575 y trasladados a Vélez-Málaga en 1577. Véase J.E. LÓPEZ DE COCA CASTAÑER. "Nuevo episodio en la historia del azúcar 
de $1552^{24}$, mientras que para Canarias aparte de las compilaciones publicadas, hemos acudido a la documentación original que, en algunos casos, presentan variables más o menos significativas como en el caso de las ordenanzas de Tenerife, editadas por Núñez de la Peña, en la pasada centuria por Peraza de Ayala, las llamadas Ordenanzas Viejas conservadas en el Archivo Municipal de La Laguna, y las de Gran Canaria compiladas en el llamado Libro Rojo y las Ordenanzas del Concejo $^{25}$. También hemos acudido a documentación conservada en los Archivos Nacionales y especialmente en el Archivo General de Simancas, en la sección Registro General del Sello donde se custodian ordenanzas anteriores a las compilaciones señaladas que contribuyen a llenar algunos vacíos, como por ejemplo la acusación a dos comerciantes por incumplir la ordenanza que obliga a vender el azúcar a precios superiores a 300 mrs. ${ }^{26}$. Hemos consultado asimismo la documentación de cada uno de los concejos de las islas de realengo, concretamente los libros de sesiones capitulares en los casos que se conservan, teniendo en cuenta que no todos los acuerdos que aparecen reflejados en las actas capitulares pasaron a formar parte de las ordenanzas de la localidad, como veremos en el desarrollo del trabajo.

En ocasiones anteriores nos habíamos ocupado de la legislación local en relación con la caña de azúcar en las denominadas islas azucareras de Gran Canaria, La Gomera, La Palma y Tenerife ${ }^{27}$ en la que habíamos planteado las analogías y diferencias pero circunscritas al ámbito canario, partiendo de las Actas capitulares, las ordenanzas locales y la documentación estatal. A través de la documentación regia, provisiones y mercedes reales, conocemos algunas disposiciones que afectan al complejo agroindustrial azucarero y sobre todo en las disposiciones de la corona a los concejos ${ }^{28}$. Generalmente coexiste la ordenación municipal plasmada en las ordenanzas con el ordenamiento regio, pero también constituye una fuente significativa de datos el análisis de los autos judiciales, a través de los que pode-

de caña. Las ordenanzas de Almuñécar (Siglo XVI)”, La ciudad hispánica, siglos XIII al XVI. Madrid, 1987 , pp. 459 y ss.

24. Las ordenanzas de Granada fueron reeditadas en 1672 y en el año 2000 una edición comparada que es la que utilizamos. Ordenanzas de Granada de 1552, Introducción por A. LÓPEZ NEVOT. Ayuntamiento de Granada, 2000.

25. Para Gran Canaria las ordenanzas publicadas son: P. CULLEN DEL CASTILLO. Libro Rojo de Gran Canaria. Las Palmas de Gran Canaria, 1995 y F. MORALES PADRÓN. Las Ordenanzas del Concejo de Gran Canaria (1531). Las Palmas de Gran Canaria, 1974; para Tenerife hemos consultado las llamadas Ordenanzas Viejas, conservadas en el Archivo Municipal de La Laguna, y la edición de J. PERAZA DE AYALA. Las antiguas ordenanzas de la isla de Tenerife. Notas y documentos para la historia de los municipios canarios. La Laguna, 1935; para La Palma: A. VIÑA BRITO y E. AZNAR VALlEJO. Las Ordenanzas del Concejo de La Palma. Santa Cruz de La Palma, 1993; para las ordenanzas de La Gomera sólo disponemos de compilaciones posteriores, del siglo XVIII.

26. 1499, noviembre, 2. A. VIÑA BRITO y F. MACÍAS MARTÍN. (dir. y coord.) Documentos relativos a Canarias en el Registro General del Sello de Corte. La Laguna, FRC, 2012, doc. 500. El acuerdo del cabildo de Tenerife relativo al precio del azúcar está datado en el año 1504.

27. A. VIÑA BRITO y M. RONQUILLO RUBIO. "El control normativo del azúcar en Canarias", Açucar e o Quotidiano. Madeira, 2004, pp. 303-341.

28. A. VIÑA BRITO et al. Reales Cédulas, Provisiones y Privilegios de la isla de Tenerife (1476-1531), Santa Cruz de Tenerife, 2006. 
mos encontrar referencias al ordenamiento sobre el azúcar como prueba documental de vulneración de la norma.

Antes de pasar a analizar los paralelismos, diferencias e influencias es necesario recordar que para el caso de Canarias, al igual que otros lugares de la corona castellana, las ordenanzas emanan de los cabildos, pero era necesaria la confirmación regia. Al existir un único concejo para cada isla, su ámbito jurisdiccional y, por tanto, la aplicación del ordenamiento local quedaba circunscrita, a diferencia por ejemplo de lo que sucedía en Madeira donde las principales poblaciones tenían su propio ordenamiento.

Se observa además, que desde la incorporación de las islas a la corona castellana se arbitraron importantes medidas proteccionistas con la finalidad de asentar y afianzar a la población que acudía al archipiélago. Así se observa en la Provisión dada en Salamanca el 25 de febrero de 1506 a las tres islas de realengo, que no se venda yngenio ni heredamiento a persona poderosa ni de fuera destas islas, y así fue mandado pregonar por el gobernador Lope de Sosa: que ningún vecino ni otra persona vendiese yngenio ni heredamiento a ningun grande, ni a otra persona poderosa $a^{29}$.

Otro aspecto que se debe tener en cuenta es la cronología pues, como hemos mencionado con anterioridad, no todas las ordenanzas son de la misma época, aunque las sucesivas recopilaciones de los siglos XVI y XVII sí recogen la estructura económica básica de cada una de las áreas y, en la mayoría de las ocasiones, los cambios o añadidos son muy escasos. Generalmente las nuevas ordenanzas suponen la adaptación a nuevas realidades, como se observa por ejemplo en las Ordenanzas de La Habana de 1574, aprobadas en 1578, y confirmadas con pequeñas modificaciones por Real cédula de 27 de mayo de 1640 por la real Audiencia de Santo Domingo. En otras ocasiones se trata de recopilaciones de actas capitulares o en misivas regias ${ }^{30}$ como sucede con las ordenanzas de La Palma o las analizadas por López de Coca para Almuñécar (1574).

Probablemente la mayor presencia de ordenanzas o compilaciones en el siglo XVI está en estrecha relación o, quizá mejor, es consecuencia de la influencia e interés de la corona, al aplicarse en todo el territorio, de integrar en el ordenamiento local las normas generales emanadas de los órganos de poder.

Resulta complicado llevar a cabo una sistematización de los datos referentes a las ordenanzas relativas a la actividad azucarera en todas sus fases, no sólo por estar dispersas, sino también porque en algunas zonas son relativamente abundantes, mientras que en otras donde la actividad económica fue semejante el ordenamiento fue muy escaso, como sucedió en Gran Canaria y en La Palma, ambas islas azucareras. Mientras para la primera el número de ordenanzas es abundante, en la segunda es muy pobre, debido en parte a que solo se conserva la recopilación de 1611 y algunas referencias en las actas del cabildo, pero también porque esta isla

29. P. CULLEN DEL CASTILLO. Ob. cit., p. 175.

30. En La Habana y en La Palma carecemos prácticamente de actas capitulares para la primera mitad del siglo XVI pues ambas ciudades fueron pasto de las llamas por los piratas franceses: en 1538 y 1555 la ciudad de La Habana, y en 1553 la isla de La Palma. 
pertenecía al mismo corregimiento que la de Tenerife, por lo que posiblemente solo se señalaría en su ordenamiento las especificidades propias, sin olvidar que en La Palma al estar el consumo tan generalizado y ser muy habitual no sorprende la escasez de este tipo de ordenanzas.

Las referencias a las ordenanzas de La Gomera resultan muy tardías y lo mismo sucede con las de La Habana, sin duda el principal territorio azucarero del Nuevo Mundo, aunque el desarrollo de la industria azucarera no se iniciará hasta bien avanzado el siglo XVI, recordar que el cabildo concedió tierras para caña dentro del radio de ocho leguas reservado por las ordenanzas municipales para la producción de mantenimientos, levantándose los primeros ingenios por personas acomodadas. La caña había llegado en época del primer gobernador Diego Velázquez ${ }^{31}$ y posiblemente por ello en esas primeras ordenanzas conservadas solo aparece una mención al azúcar y más concretamente a sus derivados, en el artículo 38:

Que el diputado haga todas las posturas y cuales derechos haya de llevar por las del vino, frutas secas, jabón y confites $^{32}$; Item que a los confiteros les ponga posturas de los confites que aqui hicieren dándole a todos los dichos ganancia moderada, y que se les ponga dos veces cada año y no mas; $y$ si hicieren muchos géneros de confitura y conservas, que a todas les ponga postura, pero que no pueda llevar, aunque sea mucho género, más de una libra de confites por todas las dichas posturas $^{33}$.

No debe extrañarnos esta disparidad pues, en el siglo XIX cuando Cuba tiene una industria azucarera pujante, el ordenamiento prácticamente no refiere sino en contadas ocasiones ordenanzas sobre el azúcar.

La misma situación encontramos en Madeira. A. Vieira ${ }^{34}$ compara las ordenanzas de Canarias y la de los archipiélagos de Madeira y Azores, cuantificando los porcentajes de ordenanzas genéricas sobre azúcar, las relativas a los purgadores, almocrebes, etc., el investigador madeirense destaca el número de las existentes para Gran Canaria respecto a las de otras islas atlánticas ${ }^{35}$.

Otro aspecto que no podemos obviar en este análisis es que al articular las ordenanzas la vida local, su elaboración estaba influida por los intereses representados en el regimiento, convirtiéndose este en el fiel representante de una particularidad de intereses que hemos centrado en el azúcar, pero que podemos generalizar a las nuevas sociedades del atlántico cuyo motor económico estuvo en estrecha

31. R. GUERRA. Azúcar y Población en las Antillas. La Habana, 1970³, p. 42.

32. http://es.scribd.com/doc/44306070/ Zamora-y-Coronado-José-Biblioteca de legislación ultramarina (Consulta el 1-11-2012).

33. C. AZPEYTIA: http://www.historiacocina.com/es/historia-del-azucar (Consultado 31-10-2012).

34. A. VIEIRA. "Introduçao a o Etudo do Direito Local Insular. As posturas de Madeira, Açores e Canarias nos séculos XVI e XVII”, VII CHCA. Las Palmas de Gran Canaria (1986), pp. 673-711.

35. En Funchal se dieron 28 ordenanzas genéricas sobre azúcar, 6 sobre los almocrebes, 3 para los maestros de azúcar y 1 para el purgador; en Azores se conservan las de Villafranca con 6 ordenanzas sobre azúcar y de Angra 1 sobre azúcar y 1 para los confiteros. En Gran Canaria 55 ordenanzas sobre azúcar, 9 para los confiteros y 1 para el maestro de azúcar y en Tenerife 21 genéricas sobre azúcar, 2 para los almocrebes y 1 para el purgador. 
relación con el azúcar y que resultó de una simbiosis del ordenamiento regio con los usos y costumbres de cada concejo.

Con la finalidad de establecer los paralelismos existentes plantearemos una serie de epígrafes que aluden a las principales fases por las que pasa el azúcar desde su cultivo, proceso de transformación, derivados y exportación, añadiendo puntualmente aquellos elementos necesarios que intervienen en todo el proceso (personal, agua y madera).

Como ya señalamos, si bien nos centraremos en el ordenamiento del azúcar en el mundo atlántico las referencia al área castellana y especialmente al reino de Granada resultan ineludibles ${ }^{36}$, pero en este caso nos limitaremos a la etapa posterior a la conquista castellana y no al azúcar en el mundo andalusí sobre el que disponemos ya de una abundante bibliografía. Esta situación supone, desde el punto de partida, unas diferencias singulares pues en el territorio granadino se cuenta con una experiencia anterior y una mano de obra especializada, mientras que en el mundo atlántico si bien la mano de obra especializada pasa de Madeira a Canarias y de aquí al Nuevo Mundo con un incremento considerable de la población esclava del continente africano, los ordenamientos se van adaptando a los cambios y nuevos espacios que se ponen en cultivo.

A pesar de estas diferencias iniciales, existieron estrechas relaciones en todos los ámbitos. Baste comprobar, a modo de ejemplo, el caso de Martín Centurión y Agustín Ytalian, mercaderes genoveses, quienes manifestaron su deseo de fabricar paños y sedas en Granada y Málaga, así como azúcar en Almúñecar ${ }^{37}$, mercaderes que a su vez tuvieron fuertes intereses azucareros en Tenerife ${ }^{38}$. Este trasvase e intereses en distintas áreas fue bastante frecuente, como podemos conocer por ejemplo a raíz de la información proporcionada por un pleito que tuvo lugar en el año $1516^{39}$ protagonizado por los vecinos de Algeciras para que no se permitiera plantar caña de azúcar a Francisco Piña en el río de la Miel, contra la iniciativa llevada a cabo por un mercader de Gran Canaria en la que participaba el marqués de Tarifa y otros hombres de negocios. En el mismo sentido de este trasvase y adaptación contamos con la real cédula de 30 de diciembre de 1595 por la que se hace extensiva a Cuba las ventajas otorgadas a los dueños de los ingenios de Santo Domingo.

36. Veánse entre otros los trabajos de A. MALPICA. "La caña de azúcar del Mediterráneo al Atlántico", Comer cultura: estudios de cultura alimentaria, 2001, pp. 97-110, o el ya clásico de S. MINTZ. Dulzura y poder: el lugar del azúcar en la historia moderna. Madrid, 1996.

37. J.E. LÓPEZ DE COCA CASTAÑER. Ob. cit., p. 465.

38. E. SERRA RÁFOLS y L. DE LA ROSA. Acuerdos del Cabildo de Tenerife, 1514-1518. La Laguna, 1965, p. 259.

39. A. MALPICA. (1995) Ob. cit., p. 34. 


\section{LAS ORDENANZAS DEL AZÚCAR}

El primer hecho que llama la atención es el conjunto de medidas proteccionista relativas al cultivo de la caña que contienen las ordenanzas, tanto en el área atlántica como en el sureste peninsular. Almuñécar, Salobreña o Motril constituyen buenos ejemplos:

el principal trato y granjeria de los vecinos desta cibdad es el criar y labrar las cañas de azucar y que mediante esto los dichos vecinos abitan en ella, y si cesase no se podrian sustentar y se yrian a otra parte y quedaria la tierra despoblada... ${ }^{40}$.

El acuerdo del cabildo de Motril de 1517 ordenó pregonar unas ordenanzas para que los vecinos pudieran gozar de las cañas que siembran y hacer azúcar en ellas $^{41}$, y prácticamente la misma argumentación recogen las ordenanzas de los concejos canarios.

Estas medidas proteccionistas también se manifiestan cuando las instituciones locales abogan por poner coto a la extensión de las tierras de caña pues su exceso podría acarrear la escasez de mantenimientos, como se observa por ejemplo en el Memorial que Alonso de Cáceres, oidor de la Audiencia de Santo Domingo, dirigió al rey en 1579 argumentando que la falta de mantenimientos en Santo Domingo se debía al acaparamiento de tierras para caña ${ }^{42}$. Situaciones parecidas encontramos en otros lugares, así en Canarias se permite el abastecimiento de trigo con ventajas fiscales a las islas azucareras o la exportación de madera de unas islas a otras para el mantenimiento de los ingenios como desde La Gomera al ingenio de Adeje (Tenerife) e incluso desde el año 1533 se exime del pago del almojarifazgo, un $6 \%$ en la carga y un $6 \%$ en la descarga, la madera enviada desde Tenerife y La Palma a Gran Canaria ${ }^{43}$.

Podemos encontrar muchos paralelismos en cuanto al ordenamiento en los distintos cabildos. Ya señalamos el caso de Madeira, el de Canarias o el propio cabildo de Santo Domingo que entre sus prerrogativas, reguladas en las ordenanzas, estaba la de distribuir las tierras, competencia que luego pasará a la Audiencia, pero también el nombramiento de técnicos para el control de la actividad de los azúcares con la figura del lealdador presente en todos los ámbitos o el control de las pesas y medidas, regulado desde fechas muy tempranas.

En las islas atlánticas, así como en la mayoría de las áreas azucareras, a pesar de las diferencias geográficas y jurisdiccionales, encontramos una vinculación de la producción agrícola a su transformación industrial y a su explotación comercial y ello se observa tanto en las respectivas ordenanzas como, en la práctica, en los

40. La ordenanza es de 5 de noviembre de 1574. Véase J.E. LÓPEZ DE COCA. Ob. cit., p. 487.

41. A. MALPICA. "Arqueología y Azúcar. Estudio de un conjunto preindustrial azucarero en el reino de Granada: La Palma (Motril)", La caña de azúcar en el Mediterráneo. Actas del Segundo Seminario Internacional. Granada, 1990, pp. 135-137.

42. R. GUERRA. Ob. cit., p. 37.

43. E. AZNAR VALLEJO. La integración de las Islas Canarias en la Corona de Castilla (14781526), Las Palmas de Gran Canaria, $1992^{2}$, p. 141. 
contratos recogidos en los protocolos notariales. En el análisis de la ordenanzas lo primero que debemos señalar es la estricta regulación del azúcar que prácticamente no dejaba lugar a improvisaciones. Baste recordar lo estipulado en una de la ordenanzas de Gran Canaria que obligaba a los señores de ingenio tengan cada uno en su yngenio el treslado de las hordenanças tocantes a los açucares... ${ }^{44}$. Este riguroso control tenía como objetivo velar por la calidad del producto que se convierte en el distintivo del azúcar de Canarias, pero también porque en algunas islas la mayor parte de las tierras susceptibles de regadío se dedicaron a la caña de azúcar. Otro ejemplo es el de la isla de Gran Canaria que, en la recopilación de 1531, contiene una ordenanza que refiere el principal trato que en esta ysla ay es de los açucares.

Resulta evidente la existencia de elementos comunes en las ordenanzas de Madeira, Canarias y el Nuevo Mundo, pero cada territorio presenta sus propias especificidades que vienen determinadas por las características físicas y humanas de cada uno de ellos. En todas ellas se pone de manifiesto la defensa de las plantaciones de caña como atracción del vecindario, como en el caso de Almuñécar, ya señalado en páginas precedentes, pero también una argumentación semejante encontramos para Canarias no solo con la finalidad de fijar la población sino también para premiar a quienes contribuyeron al desarrollo de este cultivo. En Gran Canaria la corona concedió carta de naturaleza al portugués Lorenzo Fernández, en recompensa de haber sido uno de los primeros en hacer azúcar en la isla ${ }^{45} \mathrm{o}$, en La Palma, confirmó en el cargo de regidor a Gabriel de Socarrates, como premio por la edificación de muchos heredamientos de azúcar ${ }^{46}$.

Al analizar los distintos ordenamientos sobre la caña de azúcar desde la plantación a la exportación del producto ya elaborado, observamos una clara influencia de las ordenanzas madeirenses en las de Canarias en lo referente a la faena agrícola, aguas, maderas y esclavos, con una reglamentación exhaustiva tanto de los oficios ligados a la producción como al transporte y transformación. Este ordenamiento plantea sustanciales diferencias con el área de cultivo mediterráneo pero este influjo de Madeira es evidente en aspectos no solo de cultivo sino también en la terminología azucarera produciéndose un trasvase de la lengua portuguesa a la castellana con palabras que quedaron incorporadas al léxico azucarero especializado en Canarias como también en toda el área americana ${ }^{47}$. En cuanto a la confitería, denominaciones y procesos para su obtención, la terminología tiene una clara influencia andaluza y especialmente del mundo árabe ${ }^{48}$ tanto en el área lusitana como castellana, aunque, como señalamos anteriormente, la regulación

44. A. VIÑA BRITO y M. RONQUILLO RUBIO. (2004) Ob. cit., p. 310 y P. CULLEN DEL CASTILLO. Ob. cit., p. 150.

45. 1502, febrero, 2. A.VIÑA BRITO y F. MACÍAS MARTÍN. Ob. cit., doc. 609.

46. El cargo se lo había concedido el Adelantado y la confirmación es de 20 de abril de 1520. A.VIÑA BRITO y F. MACÍAS MARTÍN. Ob. cit., doc. 1085.

47. C. CORRALES y D. CORBELLA. Ob. cit.

48. E. GARCÍA SÁNCHEZ. "El azúcar en la alimentación de los andalusíes", La caña de azúcar en tiempos de los grandes descubrimientos, 1450-1550. Actas del Primer Seminario Internacional. Granada, 1990, pp. 209-231. 
de la especiería en las ordenanzas canarias es superior y con mucho más detalle respecto a las peninsulares.

Por su parte, en el mundo americano las ordenanzas tratan sobre todo aspectos relativos al mercado interno, a la esclavitud y a la ganadería, mientras las de Canarias se centran en los distintos oficios, cultivo y, sobre todo, el proceso de transformación y exportación del producto.

\section{OrdenANZAS SOBRE EL CULTIVO}

Por lo que respecta al cultivo de la caña de azúcar hay que tener en cuenta que si bien en Canarias el reparto de las mejores tierras susceptibles de regadío lo fueron para plantar cañas, el sistema imperante era la explotación directa y los contratos a partido, mientras en el mundo americano predominaba la economía colonial de plantación, lo que ya plantea diferencias iniciales muy significativas, aunque en todos los lugares se produzca una importante modificación del espacio físico.

Por lo que respecta al cultivo, no son abundantes los ordenamientos relativos a los aspectos previos como la preparación del terreno para el cultivo de cañas, si bien es verdad que, como señaló Pérez Vidal $^{49}$ y específicamente para el mundo americano, tenemos referencias de las tumbas cubanas o las roças brasileiras o las referencias a "despedregar los campos" en el caso de Canarias, pues en ambas zonas previo al cultivo tuvieron que empezar por el desmonte, realizado por medio de la tala y el fuego, sin duda el trabajo más duro.

En cuanto al tipo de caña, existen algunas diferencias. Las cañas en Canarias son de longitud mayor. El humanista Hieronymus Munzer se informa en Valencia por un patrón de que en estas islas las cañas de azucar son de una longitud de seis o siete pasos y del grueso de la parte anterior del brazo ${ }^{50}$. En el mundo americano, y más concretamente en Santo Domingo, a donde se llevaron cañas de Canarias en el segundo viaje de Colón en 1493, estas cañas son llamadas criollas o de la tierra.

Por lo que respecta a las fases de cultivo en las que insisten las ordenanzas madeirenses y canarias, estas últimas recogen no tanto la actividad de los cañavereros como las obligaciones inherentes al trabajo que desarrollaban, así como la protección de los cañaverales ${ }^{51}$. Por ejemplo, se establecía la obligatoriedad de no trabajar más de dos suertes de tierra de cañas: ningun cañaverero que tomare a curar cañas de açucar pueda tener mas de dos suertes $^{52}$, vivir en el cañaveral, y si se alejaba solo podía hacerlo dos días cada mes; se le prohibía comprar caña para si mismo sin acuerdo del dueño. También encontramos ordenanzas relativas al

49. J. PÉREZ VIDAL. La cultura de la caña de azúcar en el Levante español. Madrid, 1973 , p. 23.

50. ÍDEM, p. 19.

51. Las ordenanzas de Gran Canaria dedican un importante epígrafe a los cañaverales y cañas. F. MORALES PADRÓN. (1974) Ob. cit.

52. ÍDEM, p. 115. 
proceso de plantación ${ }^{53}$, y otras medidas de control a los cañavereros entre las que destacamos la prohibición de vender o prestar agua de la que tuviese a su cargo el cañaverero para regar los cañaverales, medida fundamental en Canarias donde el agua no era abundante.

Por el contrario, sí son más frecuentes las referencias a las labores de cura en la que se incluía la poda, escarda, el riego y la vigilancia de los cañaverales, ya fuera para evitar hurtos penados duramente o la lucha contra las plagas, como recogen las ordenanzas de La Palma, las de Tenerife y las de La Gomera de la obligatoriedad de matar cinco cuervos al año, o en Madeira donde los vecinos estaban obligados a presentar un número variado de cabezas de cuervos y pájaros canarios en algunos lugares como recogen las ordenanzas de Vila Franca do Campo ${ }^{54}$.

El cuidado de las plantaciones prohibía tajantemente la entrada de ganado y esta situación aparece tanto en Almuñécar como en Motril, donde el concejo multaba con 6 mrs. por cabeza si la entrada del ganado se producía de día y el doble si era de noche, especificando que ninguna manada de vacas entre en los cañaverales, penas que se hacen extensivas a cualquier otra bestia ${ }^{55}$. La misma situación se recoge en las ordenanzas de Canarias en las que se toman una serie de medidas para que el ganado no entre en tierras de caña, y también en Madeira donde son frecuentes las ordenanzas sobre la delimitación de zonas obligatorias de pasto y de cercar las tierras cultivadas o la prohibición de tener puercos a cualquier persona que trabajase en el ingenio.

Junto a estas ordenanzas emanadas del cabildo encontramos alguna provisión real en el mismo sentido que se incorporaría al ordenamiento local como fue, entre otras, la provisión dirigida al gobernador de Tenerife ante la queja de los vecinos por los ganados que destruían los cañaverales ${ }^{56} \mathrm{o}$, con anterioridad, otra misiva real para que el concejo de Tenerife hiciera cumplir las ordenanzas relativas a las heredades, ...ya que en ellas entran ganados mayores y menores y salvajes que causan mucho daño en las cañas de azúcar y en las acequias ${ }^{57}$.

Uno de los principales acuerdos tomados para evitar la entrada de ganado en los cañaverales, a pesar de las ordenanzas que lo prohibían, fue la de cercar las plantaciones, medida que no siempre fue efectiva como se observa en La Palma, donde Jácome Monteverde, propietario unipersonal de los ingenios de Argual y Tazacorte, se queja de que algunas personas con sus ganados habían roto las cercas que protegían sus cultivos. Las Ordenanzas viejas de Tenerife insisten sobre este particular cuando señalan el quebrantamiento de las albarradas y las penas correspondientes a los infractores.

53. Ordenanzas Viejas de Tenerife, f. 66v.

54. A. VIEIRA. (1991) Ob. cit.

55. Tal como recoge una ordenanza de 3 de abril de 1520. Cit. A. MALPICA CUELLO. (1990) Ob. cit., p. 136.

56. La queja fue llevada a cabo por un propietario del norte de la isla de Tenerife, Pedro Ytalián y la provisión real esta fechada en Granada el 26 de agosto de 1526. A. VIÑA BRITO et al. Ob. cit., pp. 28-29.

57. 1507, diciembre, 4. A. VIÑA BRITO y F. MACÍAS MARTÍN. Ob. cit., doc. nº 876. 
Esta defensa de las plantaciones de cañaverales llega hasta el extremo de establecer en las ordenanzas la distancia a la que deben situarse las colmenas, como establecen las ordenanzas canarias y las de las islas antillanas.

Pero no sólo era el ganado el que destruía los cañaverales sino que se producían hurtos que estaban penalizados según establecía el ordenamiento. La apropiación de cañas debía debía ser frecuente y habitual a tenor de lo que recogen las ordenanzas. En las de Almuñécar los hurtos de caña estaban penalizados con 14 mrs., cuantía que ascendió en el año 1521 a $100 \mathrm{mrs}^{58}$. Más duros eran los castigos que recogen las ordenanzas de Motril: qualquiera persona que fuere tomada en los dichos cañaverales, aunque no le hallaren cojendolas, sea traydo a la carçel y pague dosientos maravedis de pena... ${ }^{59}$. En esta localidad se prohíbe incluso que ninguna persona recorra los campos plantados de cañas sin tenerlas sembradas, so pena de carcel y una fuerte multa y un mayor castigo para los que sean sorprendidos cogiendo cañas. También las ordenanzas canarias inciden en las penas para quienes roben cañas, pero van más allá al fijar diferentes cuantías en razón de la edad del ladrón: a los menores de 15 años, medio real por caña, y a los mayores, un real ${ }^{60}$. El ordenamiento de Madeira llevó a estipular pesadas penas para quienes robasen cañas, pero también imponía sanciones en caso de hurto de bagazo y de mieles.

Las medidas proteccionistas tendentes a mantener el cultivo en las mejores condiciones posibles dedican algunos apartados a las plagas, siendo las de ratones y gusanos las más frecuentes. Encontramos referencias a las cañas podridas ${ }^{61}$, pero también se especifica que si las cañas se hubiesen de labrar y algunas estuvieren podridas o agusanadas o comidas de los ratones que las examine el lealdador ${ }^{62}$. Estas plagas afectaron muchas de las plantaciones en Canarias, como las de los Benítez de Lugo en La Orotava, la de Los Monteverde en La Palma, temiéndose incluso por la continuidad de las plantaciones, como se observa tras la aparición de plagas de gusanos en las cañas en Güímar (Tenerife), por lo que los Acuerdos del cabildo de Tenerife señalan que se puede recrescer mucha perdida e daño a la ysla de Grand Canaria por esto está perdida y la gente della alcançada ${ }^{63}$.

Los distintos ordenamientos que hemos consultado se preocupan de regular estrictamente las labores tocantes al proceso de cura, no tanto al envarado, escarda y riego como del corte y quema del cañaveral. Las labores de poda figuraban bajo la dependencia directa de los desburgadores a los que el ordenamiento dedica varios epígrafes, aunque también hay que señalar que el corte de las cañas se hacía

58. El cabildo confirmó las penas para los que hurtasen cañas el 17 de octubre de 1521 . J.E. LÓPEZ DE COCA CASTAÑER. Ob. cit., p. 478.

59. A. MALPICA CUELLO. (1990) Ob. cit., p. 135.

60. Ordenanzas Viejas de Tenerife, ff. 67r-v. También las ordenanzas de Gran Canaria aluden a los castigos que se imponen a los ladrones de caña. F. MORALES PADRÓN. (1974) Ob. cit., p. 115.

61. Ordenanzas Viejas de Tenerife, f. 68r.

62. F. MORALES PADRÓN. (1974) Ob. cit., p. 146.

63. 1503, junio, 14. E. SERRA RÀFOLS. $\left(1996^{2}\right)$ Ob. cit., doc. no 31. 
a costa de los señores de los cañaverales, como establecían las ordenanzas de Gran Canaria ${ }^{64}$.

El proceso de poda y corte estaba estrictamente regulado en las ordenanzas canarias, especificándose los utensilios más apropiados y a quién competía esta labor. Las ordenanzas de Tenerife y las de Gran Canaria precisan que el desburgador era, al tiempo que el encargado de despuntar y desollar las cañas, cortarlas con un puñal y las ordenanzas sancionaban las posibles negligencias que pudieran cometer, si bien como señalan las de Tenerife, podía vender las hojas de las cañas una vez limpias si tenía autorización de su dueño que ningun desburgador venda cogollos sin licencia de su dueño.

En ocasiones las ordenanzas indican el instrumental que se debía utilizar, podones, puñales, cuchillos, como se establece en las de Gran Canaria ${ }^{65}$ respecto al corte de las cañas que debían hacerlo los desburgadores con puñales por sus arreas y no las arranquen ni quiebren, pues en ese caso la multa ascendía 600 mrs. También el cabildo de Tenerife legisla en el mismo sentido: los jornaleros no podían cambiar de trabajo una vez concertados con el propietario y los desburgadores debían atender personalmente el corte de las cañas, especificando que debían cortar por la base y cuidando no dañar la raiz, imponiendo severas multas a los cortadores que arrancaban las cañas en lugar de cortarlas ${ }^{66}$. Esta reglamentación fue bastante precisa en las ordenanzas de Madeira.

Como puede suponerse, en esta primera fase la reglamentación más exhaustiva hace referencia a los oficios ligados a la producción, cañaverero y desburgador y son más escasas las referencias a otro tipo de personal que interviene en la plantación y cura, como los regadores, jornaleros, etc.

Las ordenanzas sobre el azúcar no dejaban nada al azar en las labores de la caña en esta primera fase de cultivo, incluso dedican algunos epígrafes a la quema de cañaverales $^{67}$. Así establece sobre la quema de paja en los cañaverales que esta se lleve a cabo cuando se corten las cañas, siempre que se tomasen las precauciones necesarias, pues los cogollos eran quemados sobre el terreno sirviendo de abono. A los señores de ingenio se les autorizaba a hacer cenizas para sus ingenios ${ }^{68}$, lo que era necesario para el proceso de purga con la finalidad de blanquear los panes.

Sin duda la protección de los cañaverales y las ordenanzas sobre la fase de cultivo determinaban que la obtención de los azúcares alcanzara una buena calidad, de ahí el interés en controlar todo el proceso, como se observa, por ejemplo, en Motril en lo que respecta a la guarda de cañaverales. En el año 1517, el cabildo de esta localidad mandó pregonar unas ordenanzas para que los vecinos pudiesen gozar de las cañas que sembraren y hacer azúcar en ellas:

64. F. MORALES PADRÓN. (1974) Ob. cit., p. 147.

65. ÍDEM, p. 146.

66. Así se recoge en las Ordenanzas Viejas, $\mathrm{n}^{\circ} 14$ y en los Acuerdos del Cabildo de 11 de agosto de 1508. E. SERRA RÀFOLS y L. DE LA ROSA. Acuerdos del Cabildo de Tenerife, 1508- 1513. La Laguna, $F R C, 1996^{2}, \mathrm{n}^{\circ} 13$.

67. Ordenanzas Viejas de Tenerife, ff. 66r-67v. Título sobre la Quema de cañaverales.

68. F. MORALES PADRÓN. (1974) Ob. cit. Título De los fuegos, p. 139. 
ordenaron y mandaron que para que los cañaverales que tienen los vecinos desta villa esten guardados y cada uno goze de lo que sembrare por quanto ay buen recabdo para en el haser del açucar dellas, hisieron las hordenanças siguientes ${ }^{69}$.

En Madeira, y sobre todo en Canarias, generalmente los grandes propietarios de plantaciones de caña lo eran también de los ingenios, pero existía un grupo de pequeños propietarios que no disponían de molino y debían acudir a moler sus cañas a los ingenios. En el trayecto desde que se producía el corte de la caña, su atado en flejes y el acarreado por los almocrebes hasta la llegada al molino se producían robos, que asimismo eran sancionados por las ordenanzas.

Lo habitual, y así aparece recogido en numerosas escrituras tanto en Canarias como en Almuñécar y en otros lugares, era que los propietarios de cañas llevaran la producción al ingenio abonando el 50\% del azúcar obtenido de sus cañas en concepto de molienda segun lo tienen de uso y costumbre antiguamente, sin que los arrendadores pudieran percibir ninguna refaçion de mas de la dicha mitad y en el caso de Almuñécar se ordena a los propietarios que no corten sus cañas ni procedan a transformarlas hasta que concluyan los haces apartados por los vecinos o viceversa, como también se estipula los diferentes turnos en el tiempo de la molienda ${ }^{70}$.

La alternancia en la molienda queda perfectamente recogida en las ordenanzas canarias, estableciéndose turnos de molienda muy estrictos que estaban relacionados con el caudal de agua que llegaba al ingenio en diferentes épocas. La escasez de recursos hídricos en el archipiélago dio lugar a que se mantuviese mancomunado el uso del agua, como cuando se producían las particiones de los bienes entre los herederos del propietario, como se observa en la partición de la hacienda de Jácome de Monteverde entre sus 5 hijos $^{71}$. En Canarias una de las obras más costosas era la traida de agua que supuso enormes inversiones y su control era decisivo tanto para las plantaciones y molienda como también para el control social ejercido por los grandes propietarios. Por su parte en La Española y en Puerto Rico el riego estuvo asociado a la caña de azúcar, aunque no de forma exclusiva.

Resulta lógico que las tierras de caña se situasen en la red hidráulica puesto que era imprescindible el regadío y así vemos como la influencia del modelo institucional madeirense fue decisiva para la organización de la estructura institucional azoriana, que se limita a los aspectos formales. Las situaciones derivadas de esa distinta forma de explotación de los recursos implicaba una mayor atención del legislador local y no se encontraba situación similar en Lisboa, pues como ha manifestado A. Vieira los nuevos códigos de posturas en las nuevas sociedades del atlántico portugués resultan de una simbiosis del ordenamiento regio con los usos y costumbres de cada ciudad.

69. A. MALPICA CUELLO. (1990) Ob. cit., p. 135.

70. La ordenanza está datada el 5 de noviembre de 1574. J.E. LÓPEZ DE COCA CASTAÑER. Ob. cit., p. 479.

71. A. VIÑA BRITO. "La hacienda de Tazacorte (La Palma)", Anuario de Estudios Atlánticos, 50 (2004), Tomo I, pp. 545-587. 
Una de las preocupaciones concejiles en esta primera fase era la venta libre de caña de azúcar y en este caso encontramos algunas disposiciones sobre este particular y así, por ejemplo, las ordenanzas de Almuñécar prohibían la venta de cañas excepto para su exportación por vía marítima o comercio menudo en el mercado local, penalizándose la venta libre y al por mayor de la caña dulce, pues el procesamiento quedaba reservado a las plantas de transformación como veremos posteriormente.

\section{ORDENANZAS SOBRE EL PROCESO DE TRANSFORMACIÓN}

Contamos hoy en día con una interesante bibliografía relativa al proceso de transformación de la caña en azúcar, tanto del personal que intervenía en el mismo como de las distintas etapas por las que va pasando hasta la obtención del producto final y todo ello se llevaba a cabo en el ingenio donde una de las piezas principales era el molino. Sin embargo cuando se alude al molino azucarero en La Española, este combina dos funciones: la planta de un proceso agrícola y una propiedad agraria cultivada a medias, al ser utilizado el resto del terreno como reserva forestal y dentro de la otra mitad solo una parte se dedicaba a caña y el resto a cultivos de subsistencia ${ }^{72}$.

Los distintos ordenamientos, tanto en el área mediterránea como atlántica, dedican varios epígrafes a la leña y madera, básica e imprescindible para llevar a cabo la cocción de las cañas previo a la obtención de los azúcares y derivados.

Las reservas de madera eran imprescindibles para el funcionamiento de los ingenios, lo que podría contribuir a una progresiva deforestación de ciertas zonas. El concejo de Gran Canaria llegó a prohibir la tala en la montaña de Doramas y estableció un fuerte control en el corte en Tamadaba, mientras que en Tenerife se especificaron las zonas habilitadas para el corte de leña, destinándose varios epígrafes del ordenamiento a ello. La misma situación se produjo en Almuñécar, donde el concejo fijaba los lugares de recogida de la leña. Este aspecto, en sus inicios, no fue valorado en el mundo americano, aunque la transformación del medio físico fue mucho más evidente.

Nos ha llamado la atención las distintas denominaciones que recogen las actas capitulares y los ordenamientos locales para designar los lugares donde tenía lugar el proceso de transformación. En Motril, a fines del siglo $\mathrm{XV}^{73}$, encontramos aduanas de açucar que eran instalaciones donde se elaboraba el azúcar: cortar las cañas en pedazos, molienda, prensa, cocción y cristalización, mientras en el reino de Valencia se utiliza el término trapig, o ingenios como se les denomina habitualmente en el área atlántica, pero no aduana pues este término en las islas tiene la acepción del lugar donde se abonaban los diferentes impuestos a los que estaba

72. J.E. LÓPEZ DE COCA CASTAÑER. Ob.cit.

73. I. GONZÁLEZ TASCÓN y J. FERNÁNDEZ PÉREZ. "El azúcar en el viejo mundo. El impacto de su elaboración", La caña de azúcar en tiempos de los grandes descubrimientos, 1450-1550. Actas del Primer Seminario Internacional. Granada, 1990, p. 107. 
sometido el producto de cara a la exportación. Así por ejemplo en La Gomera se señala que el valor del azúcar llegó a ser tan elevado en la aduana que se le cita durante el siglo XVI, diferenciándose el 6\% del azúcar, y se afirmaba en 1557 que en los años buenos de azúcar la renta por la saca de ésta equivalía a la obtenida por el quinto y almojarifazgo de todos los demás productos ${ }^{74}$.

No entraremos a describir los distintos elementos que componían el espacio de transformación: molinos, casa de calderas, de purga..., sino las ordenanzas que afectaban a este proceso, sin duda el de mayor importancia y donde los concejos intentaron velar por la buena práctica pues de la calidad del azúcar dependía su venta y toda la economía insular. Una de las cuestiones que generó algunos problemas fue la cantidad de cañas o de azúcar que se debía abonar en concepto de maquila, pero también, como señalamos anteriormente, los turnos de molienda.

La normativa referente al funcionamiento de los molinos azucareros ocupa buena parte de las ordenanzas tanto en el área peninsular como en las islas. Las ordenanzas de Almuñécar ponen su énfasis en la obligatoriedad de los dueños y arrendatarios de molinos de tenerlos preparados y que la maquila fuese del 50\%. La misma situación se dió en Canarias, como se recoge en un documento del Registro General del Sello: las ordenanzas de los ingenios que molían las cañas a cambio de la mitad de la molienda ${ }^{75}$, especificándose en el caso de las ordenanzas de Gran Canaria que la mitad era para los señores de caña y la otra para los señores de ingenio y afectaba tanto al açucar como espumas de tachas e calderas e respumas e myeles e remyeles e rapaduras ${ }^{76}$. El ordenamiento es muy preciso en este aspecto:

Que los labradores de cañas reciban de los señores de ingenio donde molieren 15 arrobas de los refinados de la parte de las mieles del primer açucar dentro de tres meses que comenzaren a moler y el señor de ingenio obligado a refinar todas las mieles del azucar blanco, refinados, espumas y respumas, rapaduras, coguchos y pies y luego se parta por mitad, poniéndole en cuenta las 15 arrobas y de esta parte del azucar del labrador aya el señor la cuarta parte por razon del trabajo.

Posiblemente la desconfianza generada entre señores de cañas y de ingenio en el momento de la molienda llevó a que se permitiera que los señores de cañas puedan tener una persona que vea en el ingenio cuando se molieren sus cañas. La misma situación llevó a establecer que no pueda el señor de ingenio sacar del mismo los açucares del señor de las cañas sin que este lo vea ${ }^{77}$.

En alguna localidades, como sucedió en Granada, los derechos de maquila no se limitaban a la mitad del azúcar producido en cada tarea de cañas, sino que debían atender a los gastos de limpieza y transporte de la caña y al suministro de las formas de barro, como recogen las ordenanzas de Almuñécar o las de Motril

74. G. DÍAZ PADILLA y J.M. RODRÍGUEZ YANES. El señorio en las Canarias occidentales. La Gomera y El Hierro hasta 1700. Cabildo de La Gomera. Cabildo de El Hierro, 1990, p. 417.

75. 1514, diciembre, 4. A. VIÑA BRITO y F. MACÍAS MARTÍN. Ob. cit., doc. nº 1394.

76. F. MORALES PADRÓN. (1974) Ob. cit., p. 145.

77. ÍDEM, p. 149. 
en 1582 cuando se señala que cada tarea de caña de 480 arrobas hasta haçella açucar en prieto.

Por su parte las ordenanzas canarias insisten sobre todo en la cualificación de la mano de obra ${ }^{78}$ que intervenía en este proceso y así dedican varios epígrafes en el título De los açucares a la figura del maestro de azúcar o a los purgadores, a los que se prohibía abandonar el ingenio una vez iniciada su labor. Maestros de azúcar, purgadores y escumeros debían ser examinados por el cabildo ante dos personas veedores con los diputados y ante el escribano: Los maestros de azúcar, refinadores, purgadores y escumeros que trabajen sin ser examinados, 2000 mrs. y lo mismo para el sr. de ingenio que los recibiere, señalan las ordenanzas de Gran Canaria $^{79}$, estableciéndose que en cada ingenio solo podía haber un oficio de maestro, purgador, refinador y escumero. También alude al oficio desempeñado por los caldereros, que no debían ser abundantes a tenor de las medidas que tomó el cabildo de Tenerife para que el calderero Martín López no abandonase la isla porque era un buen oficial para los ingenios, que es cosa muy necesaria porque sin él la dicha isla recibiría mucho inconveniente, por eso cada señor de ingenio o su arrendador le pague cada un año dos mil mrs., que sean "muertos" para el dicho Martín Lopes y que además de esto sean obligados a le pagar las obras que el hiciere en su justo precio y los dos mil mrs. le paguen en tanto azúcar que vala ${ }^{80}$.

Esta vigilancia lleva incluso a prohibir hacer partido entre el señor del ingenio y los purgadores y maestros de azúcar, aunque fuera para las mieles o a que los purgadores, una vez que el azúcar estuviese lealdado, pudiesen hacer cambios pagara en las setenes e aya pena de ladrón ${ }^{81} \mathrm{y}$, por supuesto, a que al principio de la zafra los señores de ingenio presentasen en el cabildo al maestro, purgadores, refinadores y espumeros, jurando no hurtar las mieles, ni hacer fraude. Esta misma atención a los oficiales que intervenían en el proceso de transformación la encontramos en las ordenanzas de Madeira, tanto para los maestros de azúcar como para refinadores, purgadores y, al mismo tiempo, se exigía al señor una selección de los agentes que intervenían en el proceso y que debían prestar juramento em veraçao todos los años.

El ordenamiento interviene en todas las fases del proceso de transformación de la materia prima. Una vez purgado el azúcar era necesario dejarlo secar, generalmente en el tendal del propio establecimiento, se ponía a solear en el balcón refiere por ejemplo la partición del ingenio de La Orotava ${ }^{82}$, pero también encontramos que las ordenanzas señalan que el señor de las cañas que quisiese partir en el tendal, el señor de ingenio le entregaría la mitad de las formas para llevarlas a purgar a su ingenio y proceder, por último, a su devolución ${ }^{83}$.

78. A. VIÑA BRITO. "La organización social del trabajo en los ingenios azucareros canarios (siglos XV y XVI)", En la España Medieval, 29 (2006), pp. 359-381.

79. F. MORALES PADRÓN. (1974) Ob. cit., p. 144.

80. 1509, agosto, 17. E. SERRA RÁFOLS y L. DE LA ROSA. (1996²) Ob. cit., doc. $\mathrm{n}^{\circ} 69$.

81. F. MORALES PADRÓN. (1974) Ob. cit., p. 146.

82. Archivo Histórico Provincial de Santa Cruz de Tenerife, Sección Histórica de Protocolos Notariales, $\mathrm{n}^{\circ}$ 411, ff. $718 \mathrm{r}-722 \mathrm{r}$.

83. F. MORALES PADRÓN. (1974) Ob. cit., pp. 147-148. 
Si los oficios de maestro de azúcar, escumeros, purgadores ocupan cuantitativamente el monto principal en el proceso de transformación del azúcar, las ordenanzas también hacen especial hincapié en las llamadas formas. Para Madeira, segun el regimiento, la existencia de grandes formas era considerada perjudicial para la purgación y por ello el monarca lusitano recomendaba que tuvieran un tamaño similar y fuese fornecida con uma bitola a os oleiros del reino de modo que 6 panes de azúcar pesasen una arroba ${ }^{84}$. El interés por las formas de azúcar lo encontramos en otros muchos lugares, se obliga a que cuaje el azúcar en conos iguales y sean controlados por el fiel los olleros que lo hacian ${ }^{85}$, señalan, por ejemplo, los ordenamientos del sureste peninsular. Por su parte en Cuba, una de las causas que retrasó en gran medida la producción de azúcar a gran escala en el siglo XVI fue que los cobres y las formas no podían importarse directamente de Portugal, por la prohibición de las Leyes de Indias.

En Canarias las ordenanzas no aluden a la capacidad de las formas, pero a través de contratos notariales sabemos que los ingenios se abastecían de formas procedentes fundamentalmente de la región de Aveiro, al igual que los cobres para el melado que llegan a ser tan escasos que se primó la labor de aquellos operarios encargados de su mantenimiento. La importancia de los cobres hizo por ejemplo que en el aprecio del ingenio de La Orotava fuesen valorados tanto o más que las maderas empleadas en la edificación del ingenio con todas sus dependencias ${ }^{86}$.

Otro oficio al que las ordenanzas le dedican varios epígrafes es a la figura de los lealdadores, como se observa en las ordenanzas de Tenerife, Gran Canaria o Madeira. Este oficial del concejo tenía por misión fiscalizar el azúcar elaborado, pues de su diligencia dependía la calidad del producto apto para exportación. Pero no solo las ordenanzas aluden a esta figura sino que incluso encontramos disposiciones regias, que formarán parte del ordenamiento local, con la finalidad de llevar a cabo una protección y control para garantizar la exportación en las mejores condiciones, obligando a los cabildos al nombramiento de veedor de azúcar ${ }^{87}$, una medida de protección y control muy habitual en los documentos de la época. Este control es evidente por ejemplo en la prohibición de venta de azúcar por los oficiales del ingenio: el señor debía pagarles en dineros o en especies, pero no en azúcares para evitar una bajada de los precios ${ }^{88}$; los mercaderes no podían comprar azúcar quebrado, ni escumas, ni ceras, sin licencia del señor del ingenio ${ }^{89}$, así

84. C. TORRES. "A industria do açucar nos alvores da espansâo atlântica portuguesa”, La caña de azúcar en el Mediterráneo. Actas del Segundo Seminario Internacional. Granada, 1991, p. 196.

85. A. MALPICA CUELLO. (1995) Ob. cit., p. 29.

86. Archivo Histórico Provincial de Santa Cruz de Tenerife, Sección Histórica de Protocolos Notarial, $n^{\circ} 411$, ff. 718r-722r.

87. A. VIÑA BRITO y F. MACÍAS MARTÍN. Ob. cit., doc. nº 1494.

88. Si bien las ordenanzas de Gran Canaria prohibían pagar a los empleados del ingenio con azúcar para evitar su reventa y provocar una caída de los precios, en Tenerife el valor del azúcar como moneda solo excluye a los prestamistas de dinero y a los mozos de soldada que servían fuera de los ingenios, el resto del personal del ingenio recibía su soldada en azúcar.

89. F. MORALES PADRÓN. (1974) Ob. cit., p. 150. 
como prohibiciones sobre la reventa, como establece por ejemplo la ordenanza confirmada por la corona en el año 1537 para que no se revendan los açucares ${ }^{90}$.

El control afectaba a todas las fases de la agroindustria deteniéndose incluso en los envases para la exportación del producto, como analizaremos posteriormente. En los acuerdos del cabildo de La Palma de 29 enero de 1553 se señalaba que

en las caxas de asucar que se sacaren fuera desta ysla en ello por la saca de madera no contribuyan cosa alguna al conçejo los señores de ingenio e los arrendadores que los tuvieren a renta, siendo vs. de la ysla, sacando los dichos asucares fuera de la isla para venderlos en otra parte, porque si los vendieren.....

La legislación fue más allá y así el cabildo de Tenerife ordenó que el azúcar, una vez empapelado, se embalara en cajas de madera, que no podían ser ni de pino ni de palo blanco, siendo muy apreciadas las de tilo ${ }^{91}$.

Si la exportación de azúcar de calidad era uno de los objetivos prioritarios, en el caso de Canarias el ordenamiento precisa con todo detalle los distintos tipos de azúcares: blanco que era apto para exportar, quebrado para consumo local, mascabado, de espumas, panelas, así como las cantidades correspondientes que, tras la cocción, debían darse a los señores de caña por los señores de ingenio. Las ordenanzas de Gran Canaria fijan, para los refinados y mieles, de cada ciento arrobas de açucar blanco que se hizieren en los engenos una pipa de remyel de diez e ocho arrobas $^{92}$.

Es precisamente en el proceso de transformación donde el ordenamiento en las islas atlánticas es más minucioso, sobre todo en el control de los distintos oficiales que intervenían en el proceso, pues del azúcar dependía la mayor parte de la economía de las denominadas islas del azúcar.

\section{ORDENANZAS SOBRE LA COMERCIALIZACIÓN}

Uno de los apartados en que las ordenanzas se muestran más minuciosas es el relativo a la comercialización. Aunque en el caso de Canarias la intervención de la Corona no fue muy significativa, pero sí quedó reflejada en el ordenamiento local con una serie de normas relativas tanto a la exportación como a su venta en el interior de cada una de las islas.

La iniciativa en la exportación corrió a cargo de extranjeros ${ }^{93}$, genoveses y flamencos, en parte porque las franquicias canarias llegaron a ser casi perpetuas

90. 1537, diciembre, 24. Valladolid. P. CULLEN DEL CASTILLO. Ob. cit., p. 393. La confirmación regia lleva inserta la ordenanza del cabildo de 26 de septiembre de 1537.

91. E. AZNAR VALLEJO y A. VIÑA BRITO. "El azúcar en Canarias, escala entre dos mundos", La caña de azúcar en tiempos de los grandes descubrimientos. Actas del Primer Seminario Internacional. Granada, 1989, pp. 185-186.

92. F. MORALES PADRÓN. (1974) Ob. cit., p. 147.

93. Veáse entre otros, A. MALPICA CUELLO. (Ed.) 1492: lo dulce a la conquista de Europa. Actas del Cuarto Seminario Internacional sobre la caña de azúcar. Granada, 1994; F. MELIS. "Má- 
a cambio de un porcentaje de almojarifazgos que fueron muy bajos respecto a las ordenanzas de otras partes del reino ${ }^{94}$.

Las ordenanzas que afectaban a la exportación inciden en los distintos tipos de azúcares así como en los envases, con un estricto control por parte de los concejos, a pesar de que en algunos lugares se dieron intentos de monopolizar la industria azucarera local mediante la formación de compañías de explotación que se vieron obligadas a pagar entre 15 y 20 ducados por cada tarea de cañas, cuando el coste de la molienda y cocción de los jugos no superaba los 6 u 8 ducados, como ocurrió en Almuñécar.

Las medidas proteccionistas llevaron a que se vigilara estrechamente que no llegara azúcar fuera del producido en cada lugar como estipulan las ordenanzas de Gran Canaria: nadie puede meter azucar de fuera de la isla sin licencia del cabildo, so pena de perderla ${ }^{95}$. Pero también la legislación establecía la prohibición a los mercaderes para que no pudiesen comprar azúcar quebrado, ni escumas, ni ceras, sin licencia del señor de ingenio ${ }^{96}$, pues así se controlaba que el azúcar que se exportara fuera de la mejor calidad y que se mantuvieran los precios de mercado, como recoge por ejemplo el Libro Rojo de Gran Canaria en el apartado dedicado a los precios del azúcar ${ }^{97}$.

El carácter proteccionista es evidente en Madeira y Canarias. En la isla portuguesa en 1485 se promueve una mayor especialización de los oficios ligados a la elaboración de azúcar siendo obligatorio prestar juramento anualmente en el Cabildo, así como la fiscalización de los azúcares por medio de los lealdadores o una estricta normativa de cara a la exportación ${ }^{98}$.

Prácticamente todos los ordenamientos dedican algunos de sus capítulos a los pesos y medidas, al control sobre el abastecimiento interno y a la labor de los confiteros. Las ordenanzas se hacen eco de la necesidad de la unificación de los pesos y medidas y así se obligaba a los señores de ingenio a que dispusiesen de pesos fieles y pesas marcadas de hierro e tengan dos arrobas de hierro y una arroba, so pena de 600 mrs. La uniformidad de las pesas y medidas afectaba no solo al control que realizaban los concejos sino que también intervenían en la capacidad que debían tener las formas para la cristalización del azúcar y que para poder ser utilizadas debían contar con la autorización correspondiente. Así lo señalan, entre otras, las ordenanzas de Almuñécar que advierten a los maestros de azúcar que no

laga nel sistema económico del XIV e XV secolo", Mercaderes italianos en España. Siglos XIV y XVII (Investigaciones sobre su correspondencia y su contabilidad. Sevilla, 1976, pp. 3-65; A. VIÑA BRITO. De Brujas a La Palma. Luis Vandewalle el viejo y la consolidación de un linaje. Santa Cruz de Tenerife, 2009.

94. A. VIÑA BRITO y M. RONQUILLO RUBIO. (2004) Ob. cit., p. 304.

95. F. MORALES PADRÓN. (1974) Ob. cit., p. 147.

96. ÍDEM, p. 150.

97. P. CULLEN DEL CASTILLO. Ob. cit., p. 147.

98. A. VIEIRA. "O açucar na Madeira: produçao e comércio nos séculos XV a XVII", Producción y comercio del azúcar de caña en época preindustrial. Actas del Tercer Seminario Internacional. Granada, 1993, pp. 34-35. 
intenten asentar ninguna forma para hazer azucar en el vanco sin que esta haya sido examinada y sellada por el oficial municipal.

Este control sobre pesos, medidas y envases afectaba no solo al azúcar sino a la confitería, como estipulan las ordenanzas de Gran Canaria que especifican que estas se harían en barriles y debían presentarlas a examen, cumpliendo una serie de normas y así antes de meterlas (las confituras) en los barriles permanecían el azúcar 25 días a lo menos ${ }^{99}$. La legislación fue muy minuciosa, estableciendo que las mieles y remieles se exportaran en pipas de 12 barriles, de arroba y media cada una, y las conservas en barriles, aunque también hay constancia de la exportación de conservas en cajas. En todas las ordenanzas la vigilancia era estricta, siendo el oficio de lealdador uno de los personajes clave.

Si la regulación de la comercialización de cara a la exportación era estricta las ordenanzas también regulan el abastecimiento interno en cada una de las zonas productoras, estableciendo lugares específicos para la venta del azúcar y sus derivados como recogen las ordenanzas de La Palma que establecen que en las tiendas de mercería se venda azúcar por menudo ${ }^{100}$, mientras que las de Tenerife ordenan que los expendedores de azúcar sean los confiteros.

También se prohibía al señor de ingenio, como señalan las ordenanzas de Gran Canaria, vender azúcar a los mercaderes sin que estuviere lealdado bajo pena de una dobla por arroba. Además, las ordenanzas estipulaban la autorización para sacar sin licencia 15 arrobas de azucar bueno de quince en quince días mientras moliere su ingenio y, cuando acabare, 10 arrobas de azúcar blanco, pero prohibiendose taxativamente que ningún mercader pudiese comprar azúcar para venderlo de nuevo en la isla ${ }^{101}$. La reventa constituía, pues, una de las preocupaciones de los concejos que intentaron controlar con todas las medidas a su alcance.

Hemos señalado que las ordenanzas no solamente se ocupaban de la exportación de los azúcares sino también de las conservas y confituras. Tanto en España como en Portugal el empleo del azúcar en la confección de dulces pasó muy pronto a ser actividad propia de los confiteros, regulándose en el siglo XVI con bastante minuciosidad este oficio mediante la promulgación de las ordenanzas correspondientes en diversos territorios como en Lisboa, Granada o Canarias ${ }^{102}$. Las ordenanzas de Granada de 1552 son bastante prolijas en lo referente a los confiteros, al igual que las de Gran Canaria que dedican uno de sus epígrafes a este colectivo. Las Ordenanzas Viejas de Tenerife, por su parte, obligan a realizar los productos con un único azúcar y una única masa, sin mezclar unas camisas con otras, de manera similar a lo establecido en Madeira, mientras las del Nuevo Mundo, al menos para la primera mitad del siglo XVI, prácticamente no mencionan este tipo de producción.

99. F. MORALES PADRÓN. (1974) Ob. cit., pp. 38-39.

100. A. VIÑA BRITO y E. AZNAR VALLEJO. Ob. cit., p. 33.

101. F. MORALES PADRÓN. (1974) Ob. cit., p. 147.

102. J. PÉREZ VIDAL. Ob. cit., p. 126. 
Los distintos ordenamientos relativos al azúcar en la economía atlántica prestaron especial atención a los distintos utensilios o herramientas que presentan muchas semejanzas, con un significativo léxico que sigue la ruta azucarera.

El personal que interviene en cada una de las fases, desde la plantación a la comercialización, fue objeto de control en las ordenanzas y en este hecho se encuentra quizá una de las diferencias más evidentes que podemos observar en las fuerzas productivas de los territorios de azúcar, no tanto en el personal cualificado donde las influencias de las ordenanzas madeirenses son evidentes, sino posteriormente en el mundo americano, al que acudirán oficiales de las islas, ya fueran técnicos u oficiales. Baste recordar una cédula de Carlos V de 1519 en la que se recomendaba al gobernador de Gran Canaria, Lope de Sosa, que facilitase la salida de maestros y otros oficiales de los ingenios desde Canarias para las Indias. Los primeros trabajadores de los ingenios de Santo Domingo procedían de Canarias, por su experiencia en la fabricación de lo dulce $e^{103}$. No cabe duda que los monarcas castellanos pusieron especial empeño en la emigración especialmente a Santo Domingo de familias labradoras y expertas en la producción de azúcar donde los canarios desempeñaron un papel clave pues los peninsulares allí asentados no conseguían o no sabían como hacer, pese a múltiples intentos, que el guarapo cristalizase ${ }^{104}$.

Este trasvase prosiguió en el tiempo, pues aún en el siglo XVIII existen contratos, como el de un propietario de plantaciones en La Habana que solicita un maestro de azúcar y purgador y acude un vecino de la isla de La Palma ${ }^{105}$. La diferencia más evidente con los ingenios novohispanos reside en los esclavos que, si bien constituyeron un sector importante, su número en Canarias no fue muy superior al del personal libre vinculado a las plantaciones e ingenios, a diferencia de lo que sucedió en otros territorios azucareros atlánticos, como en La Española ${ }^{106}, \mathrm{o}$ también en Madeira, pues en ambos casos los esclavos se asocian preferentemente a la zafra y sobre ellos se ejercía un férreo control por parte de los dueños que contaban con el apoyo de las autoridades en caso de huida. En Canarias predomina un sistema mixto, explotación directa con asalariados, contratos a partido y mano de obra esclava.

\section{Conclusiones}

Las ordenanzas sobre el azúcar en las islas del Atlántico durante el siglo XVI tienen su referente en las respectivas coronas lusitana y española, pero el desarrollo alcanzado en estos territorios, con una modificación del espacio físico y una economía basada en la caña de azúcar, trajo consigo un gran desarrollo de la normativa local que, a grandes rasgos, se trasvasará al mundo americano.

103. R. CARANDE. Carlos Vy sus banqueros. Barcelona, 1990. Tomo I, p. 460.

104. A. GUTIÉRREZ ESCUDERO. Ob. cit., p. 95.

105. Archivo Histórico Provincial de Santa Cruz de Tenerife, Sección Histórica de Protocolos Notariales, $\mathrm{n}^{\circ} 857$, ff. 31r-v.

106. G. RODRÍGUEZ MOREL. Ob. cit., pp. 75-94. 
Las plantaciones de caña de azúcar modificaron el espacio físico en todos los territorios donde se desarolló esta cultura del azúcar, con especial incidencia en Madeira y Canarias y posteriormente en el mundo americano, pues la defensa de las plantaciones supuso la atracción y asentamiento de nuevos vecinos. Las diferencias geográficas marcarán la posterior evolución de esta economía, con sustanciales diferencias entre Madeira y Canarias respecto a los recursos hídricos, mucho más escasos en Canarias, al igual que los recursos forestales mucho más limitados en las islas respecto al mundo americano ${ }^{107}$.

Diferencias que se observan asimismo desde el punto de vista jurisdiccional, incluso en los territorios de ámbito castellano, como se aprecia en las peculiaridades favorables al común de los vecinos en el régimen municipal de los nuevos territorios, y así en Canarias los concejos, cuya área jurisdiccional era toda la isla, tenían una mayor capacidad legislativa respecto a sus homónimos peninsulares. El ordenamiento concejil en Canarias, y con mayor desarrollo en América, estuvo mediatizado por intereses particulares al ser la mayor parte de los señores de ingenio miembros del cabildo municipal, por lo que gobierno del territorio e intereses particulares llegan a confundirse.

La economía azucarera gozó de importantes medidas proteccionistas que se recogen tanto en el ordenamiento regio como en las ordenanzas locales, y afectaban tanto a las fases de cultivo como a las de transformación y comercialización del producto, medidas que están presentes tanto en el sureste peninsular como en los archipiélagos atlánticos y en el territorio americano. En las faenas agrícolas y en el proceso de transformación se observa un cierto paralelismo entre las ordenanzas de Madeira y Canarias, con una mayor insistencia en las ordenanzas canarias en los distintos oficios, pues en Canarias predomina un sistema mixto de explotación, así como sobre el proceso de transformación y exportación, deteniéndose incluso en la tipología de los envases, mientras que las ordenanzas americanas inciden en el mercado interno y en la esclavitud. Encontramos una clara influencia andaluza en el ordenamiento relativo a los derivados del azúcar y especialmente en la confitería como se observa a través del léxico, aunque con una mayor y más estricta regulación en las ordenanzas canarias.

En las áreas analizadas se detecta una importante presencia de mercaderes con un predominio de genoveses en el sureste peninsular, mientras en los archipiélagos atlánticos serán mercaderes genoveses y flamencos en la primera etapa y con posterioridad una presencia significativa de mercaderes de distintas nacionalidades muchos de los cuales se asentaran en las islas como grandes propietarios.

En síntesis podemos señalar que, en Canarias, la insistencia de la normativa concejil sobre el azúcar nos indica que la mayor parte de la producción se basaba en este producto la mayor parte de las tierras son açucarales; el trato principal de la isla es los açucares que en ella se hacen, referido en Gran Canaria la mayor parte de la gente se da a la fabricación de açucares, lo que nos ha permitido tomar

107. S. DE LUXÁN MELENDEZ y A. VIÑA BRITO. (dirs.) La empresa azucarera en Canarias. Siglos $X V$ - $X X$. Sevilla, 2009. 
las islas azucareras canarias como epicentro de las ordenanzas del azúcar, pues las especiales condiciones de las islas y las exenciones que disfrutaron provocaron un gran desarrollo de esta agroindustria, sobre la que la normativa concejil legisló reiteradamente, tanto en lo referente a las labores de plantación y producción como al estricto control que se ejerció sobre el proceso de cura, en la regulación de los oficiales, así como sobre la exportación, con la finalidad de mantener la calidad que identificaba el azúcar de Canarias.

\section{BIBLIOGRAFÍA}

AZNAR VALLEJO, E. La integración de las Islas Canarias en la Corona de Castilla (1478-1526), Las Palmas de Gran Canaria, 1992².

-, VIÑA BRITO, A. "El azúcar en Canarias, escala entre dos mundos", La caña de azúcar en tiempos de los grandes descubrimientos, 1450-1550. Actas del Primer Seminario Internacional. Granada, 1990, pp. 173-188.

AZPEYTIA, C. http://www.historiacocina.com/es/historia-del-azucar (Consultado 31-10-2012).

CARANDE, R. Carlos Vy sus banqueros. Barcelona, 1990.

CORRALES, C. y CORBELLA, D. "La formación del léxico azucarero en Canarias “, Seminario El azúcar y el Mundo Atlántico. XVI Coloquio de Historia Canario Americana. Las Palmas de Gran Canaria (2006), pp. 11-35.

CULlEN DEL CASTILlO, P. Libro Rojo de Gran Canaria. Las Palmas de Gran Canaria, 1995.

DE LUXÁN MELENDEZ, S. y VIÑA BRITO, A. (dirs.) La empresa azucarera en Canarias. Siglos $X V-X X$. Sevilla, 2009.

DEL RÍO MORENO, J. y LÓPEZ SEBASTIÁN, L. "El comercio azucarero antillano en el siglo XVI: el marco legal y la expectativa local", Producción y Comercio del azúcar de caña en época preindustrial. Actas del Tercer Seminario Internacional. Granada, 1993, pp. 155-180.

DÍAZ PADILLA, G. y RODRÍGUEZ YANES, J.M. El señorío en las Canarias occidentales. La Gomera y El Hierro hasta 1700. Cabildo de La Gomera. Cabildo de El Hierro, 1990.

GARCÍA SÁNCHEZ, E. "El azúcar en la alimentación de los andalusíes", La caña de azúcar en tiempos de los grandes descubrimientos, 1450-1550. Actas del Primer Seminario Internacional. Granada, 1990, pp. 209-231.

GONZÁLEZ TASCÓN, I. y FERNÁNDEZ PÉREZ, J. “El azúcar en el viejo mundo. El impacto de su elaboración”, La caña de azúcar en tiempos de los grandes descubrimientos, 1450-1550. Actas del Primer Seminario Internacional. Granada, 1990, pp. 99-130.

GUERRA, R. Azúcar y Población en las Antillas. La Habana, 1970³.

GUTIÉRREZ ESCUDERO, A. "Los canarios, el azúcar y el desarrollo agrícola de Santo Domingo (Siglo XVIII)”, Seminario El azúcar y el mundo Atlántico. 
XVI Coloquio de Historia Canario Americana. Las Palmas de Gran Canaria (2006), pp. 91-106.

http://es.scribd.com/doc/44306070/ Zamora-y-Coronado-José-Biblioteca de legislación ultramarina (Consulta el 1-11-2012).

LADERO QUESADA, M.A. “Ordenanzas Municipales y regulación de la actividad económica en Andalucía y Canarias. Siglos XIV-XVII”, II Coloquio de Historia Canario Americana. Las Palmas de Gran Canaria (1979), pp. 143-156.

LÓPEZ DE COCA CASTAÑER, J.E. "Nuevo episodio en la historia del azúcar de caña. Las ordenanzas de Almuñécar (Siglo XVI)", La ciudad hispánica, siglos XIII al XVI. Madrid, 1987, pp. 459 y ss.

LÓPEZ MORALES, H. "Orígenes de la caña de azúcar en Iberoamérica”, La caña de azúcar en tiempos de los grandes descubrimientos, 1450-1550. Actas del Primer Seminario Internacional. Granada, 1990, pp. 189-207.

MAGALHAES GODINHO, V. Os descobrimentos e a economía mundial. Lisboa, 1971. MALPICA CUELLO, A. "Arqueología y Azúcar. Estudio de un conjunto preindustrial azucarero en el reino de Granada: La Palma (Motril)", La caña de azúcar en el Mediterráneo. Actas del Segundo Seminario Internacional. Granada, 1990, pp. 123-153.

-. (ed.) 1492: lo dulce a la conquista de Europa. Actas del Cuarto Seminario Internacional. Granada, 1994.

-. (ed.) Paisajes del Azúcar. Actas del Quinto Seminario Internacional. Granada, 1995.

—. "Medio físico y territorio: el ejemplo de la caña de azúcar a finales de la Edad Media", Paisajes del Azúcar. Actas del Quinto Seminario Internacional. Granada, 1995, pp. 11-40.

—. "La caña de azucar del Mediterráneo al Atlántico", Comer cultura: estudios de cultura alimentaria, 2001, pp. 97-110.

—, FÁBREGAS GARCÍA, A. "La producción de azúcar en el ámbito doméstico", O Açucar e o Quotidiano. Madeira, 2004, pp. 29-49.

MELIS, F. "Málaga nel sistema económico del XIV e XV secolo", Mercaderes italianos en España. Siglos XIV y XVII (Investigaciones sobre su correspondencia y su contabilidad), Sevilla, 1976, pp. 3-65.

MINTZ, S.: Dulzura y poder: el lugar del azúcar en la historia moderna. Madrid, 1996.

MORALES PADRÓN, F. Las Ordenanzas del Concejo de Gran Canaria (1531), Las Palmas de Gran Canaria, 1974.

-. El comercio canario americano (siglos XVI, XVII y XVIII), Homenaje a D. Francisco Morales Padrón. Las Palmas de Gran Canaria, 2011.

PERAZA DE AYALA, J. Las antiguas ordenanzas de la isla de Tenerife. Notas y documentos para la historia de los municipios canarios. La Laguna, 1935.

PÉREZ VIDAL, J. La cultura de la caña de azúcar en el Levante español. Madrid, 1973.

POLO MARTÍN, R. El régimen municipal de la Corona de Castilla durante el reinado de los Reyes Católicos (organización, funcionamiento y ámbito de actuación), Madrid, 1999. 
RODRÍGUEZ MOREL, G. "La mano de obra esclava en las plantaciones azucareras de Santo Domingo", O Açucar e o Quotidiano. Madeira, 2004, pp.75-94. SERRA RÁFOLS E. Acuerdos del Cabildo de Tenerife, 1497-1507. La Laguna, Instituto de Estudios Canarios, Fontes Rerum Canariarum, $1996^{2}$.

-, DE LA ROSA, L. Acuerdos del Cabildo de Tenerife, 1514-1518. La Laguna, Instituto de Estudios Canarios, Fontes Rerum Canariarum, 1965.

-, DE LA ROSA, L. Acuerdos del Cabildo de Tenerife, 1508-1513. La Laguna, Instituto de Estudios Canarios, Fontes Rerum Canariarum, $1996{ }^{2}$.

TORRES, C. "A industria do açucar nos alvores da espansâo atlântica portuguesa", La caña de azúcar en el Mediterráneo. Actas del Segundo Seminario Internacional. Granada, 1991, pp. 183-206.

VIEIRA, A. "Introduçao a o Etudo do Direito Local Insular. As posturas de Madeira, Açores e Canarias nos séculos XVI e XVII", VII Coloquio de Historia Canario Americana. Las Palmas de Gran Canaria (1986), pp. 673-711.

—. "As posturas municipais dos Açores e Madeira nos séculos XV a XVII", Boletim do Instituto Histórico da Ilha Terceira, Angra do Heroismo, XLIX (1991), CEHA Biblioteca Digital.

—. "O açucar na Madeira: produçao e comércio nos séculos XV a XVII", Producción y comercio del azúcar de caña en época preindustrial. Actas del Tercer Seminario Internacional sobre la caña de azúcar. Granada, 1993.

VIÑA BRITO, A. "La hacienda de Tazacorte (La Palma)", Anuario de Estudios Atlánticos, 50 (2004), Tomo I, pp. 545-587.

-. "La organización social del trabajo en los ingenios azucareros canarios (siglos XV y XVI)", En la España Medieval, 29 (2006), pp. 359-381.

—. et al. Reales Cédulas, Provisiones y Privilegios de la isla de Tenerife (14761531), Santa Cruz de Tenerife, 2006.

- De Brujas a La Palma. Luis Vandewalle el viejo y la consolidación de un linaje. Santa Cruz de Tenerife, 2009.

-, AZNAR VALLEJO, E. Las Ordenanzas del Concejo de La Palma. Santa Cruz de La Palma, 1993.

- MACÍAS MARTÍN, F. (dir. y coord.) Documentos relativos a Canarias en el Registro General del Sello de Corte. La Laguna, FRC, 2012.

-, RONQUILLO RUBIO, M. "El control normativo del azúcar en Canarias", Açucar e o Quotidiano. Madeira, 2004, pp. 303-341.

-, RONQUILlO RUBIO, M. "El primer ciclo del azúcar en Canarias. Balance historiográfico", Seminario El azúcar y el mundo Atlántico. XVI Coloquio de Historia Canario Americana. Las Palmas de Gran Canaria, 2006, 239-266.

Fecha de recepción del artículo: marzo 2013

Fecha de aceptación y versión final: julio 2013 
